\title{
PROPOSTA DE IMPLEMENTAÇÃO PARA PROMOVER A FAMÍLIA NA GESTÃO ESCOLAR PARTICIPATIVA COMO FORMA DE CONTRIBUIR COM A EDUCAÇÃO DAS CRIANÇAS: ESTUDO DE CASO ESCOLA MUNICIPAL GOVERNADOR EDUARDO RIBEIRO
}

\section{ARTIGO ORIGINAL}

PEREIRA, Ramonita Silva ${ }^{1}$, CORREA, Jonatas Lima ${ }^{2}$, SILVA, Fernanda da Silva e ${ }^{3}$, ALMEIDA, Victor da Silva ${ }^{4}$, ROBERTO, José Carlos Alves ${ }^{5}$

PEREIRA, Ramonita Silva. Et al. Proposta de implementação para promover a família na gestão escolar participativa como forma de contribuir com a educação das crianças: estudo de caso escola municipal Governador Eduardo Ribeiro. Revista Científica Multidisciplinar Núcleo do Conhecimento. Ano 06, Ed. 05, Vol. 03, pp. 132-155. Maio de 2021. ISSN: 2448-0959, Link de acesso: https://www.nucleodoconhecimento.com.br/administracao/forma-de-contribuir, DOI: 10.32749/nucleodoconhecimento.com.br/administracao/forma-de-contribuir

${ }^{1}$ Graduanda do curso de Administração.

${ }^{2}$ Graduando do curso de Administração.

${ }^{3}$ Graduanda do curso de Administração.

4 Coorientador. Mestre em Engenharia de Processos. Pós-Graduando em Neuropsicopedagogia Institucional. Especialista em Gestão Estratégica de RH. Graduado em Administração e Pedagogia.

${ }^{5}$ Orientador. Mestrado profissional em Engenharia de produção. Especialização em Gestão em Logística empresarial. Graduação em Administração com Ênfase em Marketing.

RC: 84503

Disponível em: https://www.nucleodoconhecimento.com.br/administracao/forma-de-contribuir 


\section{RESUMO}

Este artigo tem como objeto de estudo a Escola Municipal Governador Eduardo Ribeiro - Manaus - AM. Seu objetivo geral consiste em saber como a participação das famílias na manutenção das dependências da Escola Municipal Governador Eduardo Ribeiro pode contribuir para a qualidade da educação que é oferecida às crianças. Como resposta, torna-se necessário demonstrar a importância que a família tem no contexto escolar, sua relação com a escola e com tudo que permeia a educação de seus filhos; bem como ressaltar a importância e o papel que a escola desempenha na vida e em todo o processo que envolve a educação de seus alunos. Além disso, este estudo de caso propõem algumas ações interventivas, por meio da ferramenta $5 \mathrm{~W} 2 \mathrm{H}$, a fim de solucionar alguns dos problemas apresentados no setor de recursos humanos e também como forma de permitir que as famílias estejam inseridas ativamente na gestão escolar, participando da educação das crianças. Tal estudo, caminha por uma metodologia de abordagem qualitativa, com a finalidade descritiva e de natureza aplicada. Assim, esta pesquisa procura propor soluções, de modo a criar benefícios a essa instituição e que permitam incluir as famílias no contexto da escola, pois esses benefícios podem contribuir para que a Escola Municipal Governador Eduardo Ribeiro possa oferecer às crianças uma educação de excelência e qualidade.

Palavras-chave: Família, educação, escola, gestão escolar.

\section{INTRODUÇÃO}

As escolas públicas de educação infantil têm enfrentado muitos problemas quando se trata de oferecer uma educação de qualidade às crianças; principalmente em relação à participação mais ativa da família no ambiente escolar, assim como oferecer condições seguras e adequadas aos alunos, de modo a permitir uma melhor aprendizagem e qualidade do ensino. Assim, é imprescindível a participação da família na gestão escolar, o que dá a elas a oportunidade de estarem inseridas

RC: 84503

Disponível em: https://www.nucleodoconhecimento.com.br/administracao/forma-de-contribuir 
ativamente no contexto escolar dos alunos; não apenas no sentido de transmitir conhecimento, mas também de preservar e cuidar do patrimônio das crianças.

Diante disso, como a participação da família na manutenção das dependências da Escola Municipal Governador Eduardo Ribeiro pode contribuir para a qualidade da educação oferecida aos alunos?

Nesse contexto, a proposta apresentada por este estudo de caso visa o objetivo de promover a participação da família na gestão escolar participativa, de forma prática, por meio da preservação, do cuidado, do zelo e da manutenção das dependências da Escola Municipal Governador Eduardo Ribeiro.

Portanto, a fim de alcançar o objetivo proposto, é necessário demonstrar a importância da gestão escolar participativa / democrática, ressaltar a importância da família no ambiente escolar, descrever a importância da escola, bem como propor ações que permitam a atuação prática dos pais na escola; pois cuidar da escola é também uma atitude de respeito, cuidado e amor pela educação dos seus filhos.

Nesse sentido, o tema proposto nesse estudo de caso justifica-se pelo fato de poder permitir que as famílias se envolvam com a educação das crianças e tenham conhecimento de suas necessidades dentro e fora da escola. Pois a responsabilidade dos pais também passa pela preservação do patrimônio escolar.

Desse modo, este estudo de caso percorre uma abordagem qualitativa, de natureza aplicada; pois a coleta dos dados ocorreu por meio de pesquisas biográficas, visita in loco, questionários e entrevistas, a fim de conhecer as necessidades da instituição de ensino, desenvolver a pesquisa e assim apresentar possíveis soluções.

Para tanto, a pesquisa divide-se em três sessões, a saber: o referencial teórico relacionada à temática em estudo; em seguida, a metodologia utilizada por este estudo e, por fim, os resultados e discursões direcionados às ações interventivas, que

RC: 84503

Disponível em: https://www.nucleodoconhecimento.com.br/administracao/forma-de-contribuir 
buscam possibilitar o envolvimento das famílias na gestão e na manutenção das dependências da Escola Municipal Governador Eduardo Ribeiro.

\section{REFERENCIAL TEÓRICO}

O referencial teórico visa esclarecer e/ou descrever uma revisão sobre o assunto abordado. Um dos pontos de partida na investigação, que é formado por um repertório de elementos que busca dá fundamento à pesquisa.

Para Chemim (2012) o objetivo do referencial teórico, dentre outros, é ressaltar e sintetizar as ideias já descritas por outros indivíduos, fazendo uma comparação com outros autores; bem como relatar a evolução do conhecimento a respeito do tema, elucidando críticas, elogios e interpretações, de modo a contribuir para o progresso do conhecimento.

Assim, é primordial que a pesquisa tenha uma correlação com a teoria, ou seja, sirvase de um referencial teórico ligado ao seu universo, como suporte de apoio que estabelece um vínculo entre o conhecimento existente e o assunto pesquisado, com a intensão de contribuir para sua elaboração.

\subsection{A GESTÃO PARTICIPATIVA NA ESCOLA}

Gestão participativa se refere à forma como uma instituição é administrada. Condiz como uma prática democrática de gestão. Pois o ato de administrar uma organização não fica limitado apenas ao seu alto escalão; mas, sobretudo, é compartilhado com todos os colaboradores, ou seja, seus participantes têm a liberdade para tomar decisões, apresentar suas ideias e encontrar soluções que possam indicar o melhor caminho e a melhor forma de conduzir uma instituição.

Em se tratando de gestão escolar participativa, Luck (2017) compreende-se como aquela que estabelece uma comunicação efetiva, possibilita um diálogo democrático entre seus participantes, promove o envolvimento da comunidade escolar na criação

RC: 84503

Disponível em: https://www.nucleodoconhecimento.com.br/administracao/forma-de-contribuir 
e aplicação do projeto político-pedagógico, mediante a uma atuação compartilhada e responsável pela educação de todos.

Desse modo, a participação na gestão de uma escola deve ter como característica uma relação democrática entre todos os seus participantes, que precisam estar alinhados no mesmo propósito de cuidar da educação de todos, de forma integrada e participativa, em que os envolvidos saibam das suas responsabilidades, da sua importância e contribuição na construção e no desenvolvimento da educação.

Portanto, a gestão participativa/democrática na escola versa por uma maior aproximação, uma participação ativa da comunidade, das famílias, dos estudantes e dos colaboradores para que possam decidir sobre a gestão escolar, apresentando ideias e soluções de como conduzi-la da melhor forma, de tal modo que essas decisões não fiquem restritas somente à direção da escola, mas possam ser compartilhadas com todos, decidindo coletivamente sobre o melhor caminho a ser seguido e que direcione a escola ao sucesso educacional.

\subsection{A IMPORTÂNCIA DA FAMÍLIA NA ESCOLA}

A família é vista como um dos elementos essências na formação educacional de suas crianças; porque é a partir dessa instituição que elas começam desenvolver sua aprendizagem e tem os primeiros contatos com o ensino. Ademais, é dentro do círculo familiar que ela aprende a socializar-se, a desenvolver seu caráter e a manter relações de respeito com o próximo, o que permite à criança dá os primeiros passos para a vida em sociedade. Santana (2016, p. 2) explica que.

\footnotetext{
A família é uma instituição essencial para o desenvolvimento do ser humano, pois desempenha funções sociais, culturais, políticas e educacionais, que culminarão na formação da personalidade, com todas as expressões culturais do meio em que a criança vive.
}

Porquanto, é de suma importância o envolvimento da família no contexto escolar, pois sua participação ativa tem grande valor no processo educacional de suas crianças.

RC: 84503

Disponível em: https://www.nucleodoconhecimento.com.br/administracao/forma-de-contribuir 
Uma vez que ela, em conjunto com a escola, também tem a responsabilidade de proporcionar uma educação de qualidade às crianças.

No entanto, há muitos fatores que dificultam um maior aproximação dos país na vida e no âmbito escolar de seus filhos, por exemplo, a carga horária de trabalho dos país compromete, em grande parte, um melhor relacionamento entre os pais e a escola; pois muitos deles não dispõem de tempo suficiente para dedicar uma maior atenção aos filhos e assim ajudá-los na resolução das tarefas e nas outras atividades. Nesse contexto, Ferreira (2018, p. 10-11) esclarece que.

\begin{abstract}
Esses empecilhos devem ser objetos de reflexão pela família e pela escola, pois são circunstâncias que interferem na maneira com que ambas as partes se relacionam, dentro de uma dinâmica que precisa ser superada. Existe também a questão da falta de tempo, colocada como empecilho pelas famílias que, muitas vezes, afirmam que por razão dos empregos, não possuem tempo para comparecer às reuniões escolares dos seus filhos e nem participar das tarefas diárias, ficando a educação em segundo plano.
\end{abstract}

Visto que a família pode e deve contribuir para que a educação produza de fato uma aprendizagem de qualidade e um efeito duradouro na vida das crianças, torna-se necessário encontrar formas que possam ajudá-las a terem um maior envolvimento na vida escolar das crianças, de modo que atendam às suas necessidades e viabilizem um bom relacionamento entre família e escola; garantindo uma formação de qualidade, com vistas ao desenvolvimento das crianças quanto à sua educação.

\title{
2.3 A IMPORTÂNCIA DA ESCOLA
}

A escola é uma instituição de grande valor para a sociedade, uma vez que ela é também uma das responsáveis na formação de novos cidadãos. Um lugar de referência socioeducacional que, em sua essência, transmiti o saber, os valores e os princípios de cidadania como parte fundamental na construção da educação.

O espaço escolar é o lugar privilegiado que possibilita a experiência da empatia, ou seja, aprender a se colocar no lugar do outro e analisar a situação do ponto de vista dele. Ao longo da escolaridade e das

RC: 84503

Disponível em: https://www.nucleodoconhecimento.com.br/administracao/forma-de-contribuir 
vivencias fora da escola, essas aprendizagens vão se constituindo em um modo de ser, de se relacionar, que o aluno levara para toda a vida. (CEDAC, 2019, p. 15).

Pois, é nesse ambiente de ensino que se busca construir e compartilhar experiências e conhecimentos para crianças, adolescentes, jovens e adultos, dignos de uma formação e uma aprendizagem de qualidade, que lhes permitam adentrar na vida profissional, fazer parte deste mundo em constante mudanças; bem como respeitar e conviver com uma sociedade que apresenta inúmeras diferenças.

Assim, Machado; Barros e Amorim (2020) relatam que a partir do instante que o ambiente escolar se torna um lugar de integração e criação de conhecimento e que passa a permitir uma visão ampla do mundo, também passa a promover e garantir aos alunos os alicerces para uma atuação ativa e consciente na sociedade.

Desse modo, é importante que a escola tenha uma cultura de prática ativa do estudante, provendo recursos e ferramentas que dê a ele a possibilidade e capacidade de conseguir resolver problemas, não sendo apenas um mero receptor de conhecimento. Ademais, isso permite que aluno aprenda de fato o conteúdo que lhe é transmitido, sinta-se seguro para colocar em prática todo o ensino que recebeu e recebe de seus educadores, com plena consciência de que é capaz de produzir, articular, analisar e desenvolver uma mentalidade crítica do mundo que o cerca.

Ao agir desse modo, a escola contribui para pleno desenvolvimento do aluno, ressalta, portanto, a sua importância para a sociedade, contribui efetivamente para a qualidade da educação e cumpre seu propósito de educar, ensinar e formar novos cidadãos prontos a atuar no mundo e dispostos a enfrentar os desafios que se apresentam na sociedade e, assim, desempenhar bem o seu papel de cidadão.

\subsection{A RELAÇÃO FAMÍLIA E ESCOLA}

A relação família e escola apresenta-se como um dos desafios por que passa a educação durante toda a sua história. E um desses desafios começa pela

RC: 84503

Disponível em: https://www.nucleodoconhecimento.com.br/administracao/forma-de-contribuir 
responsabilidade que cada uma dessas instituições tem em relação a tudo o que diz respeito à educação dos alunos dentro e fora da escola.

Entretanto, essa responsabilidade de educar não é tarefa fácil para essas instituições, principalmente pelo fato de a sociedade está em constante mudança, devido aos inúmeros estilos de vida, às diferentes profissões que aparecem e desaparecem e às fortes transformações socioeconômicas, políticas e ambientais que complicam ainda mais essa árdua e complexa missão de educar. (CEDAC, 2019).

E é nesse contexto de mudanças que acontecem muitos dos atritos na relação entre a família e a escola. Pois, devido às demandas do cotidiano de muitos pais, a educação das crianças acaba por ficar em segundo plano e tal responsabilidade passa a ser delegada a outros e principalmente à escola. Cita-se, por exemplo, um dos maiores empecilhos é a falta de tempo dos país para se envolverem no contexto escolar. Por sua vez, a escola espera um maior envolvimento dos pais na da vida escolar dos seus filhos e estejam dispostos a participar das atividades desenvolvidas na escola e cumpram seu papel de também ensiná-los, não atribuindo essa missão somente à escola. Diante disso, Silva (2017, p. 54) aponta que.

\begin{abstract}
A busca de uma boa relação entre família e escola deve fazer parte de qualquer trabalho educativo que tem como foco a criança. Além disso, a escola também exerce uma função educativa junto aos pais, discutindo, informando, aconselhando, encaminhando os mais diversos assuntos, para que família e escola, em colaboração mútua, possam promover uma educação integral da criança. Uma relação baseada na divisão do trabalho de educação de crianças e jovens, envolvendo expectativas recíprocas.
\end{abstract}

Além disso, é fundamental que essa relação entre família e escola seja pautada pelo diálogo e compreensão, não adotando uma postura de julgamentos, exigências e críticas excessivas, mas entendo que ambas as instituições têm suas limitações e enfrentam desafios a todo o momento. Pois essa relação perdurará por muito tempo, ou seja, no decorrer do desenvolvimento da criança em casa e na escola.

RC: 84503

Disponível em: https://www.nucleodoconhecimento.com.br/administracao/forma-de-contribuir 
Portanto, que essa união se construa num relacionamento de interdependência, orientada para 0 alcance de objetivos semelhantes, que melhor atendam às necessidades de toda a comunidade escolar e contribuam para o progresso da educação das crianças.

\section{MATERIAIS E MÉTODOS}

Por toda a história da humanidade, o homem se depara com problemas que exigem soluções. Como resolver problemas não é tarefa fácil, é necessário que se encontrem formas de como chegar a uma possível solução. Nesse contexto, entra o papel do método científico, o qual tem por função mostrar o caminho, orientar, conduzir e definir as etapas necessárias para se alcançar o objetivo pretendido.

Na visão de Lakatos e Marconi (2017), o método pode ser definido como um arranjo de atividades que estabelecem o caminho pelo qual seja possível atingir o objetivo de criar conhecimentos verídicos, identificar erros e ajudar as decisões dos cientistas, dentro de uma esfera segura e econômica.

Nesse sentido, o método adotado por esta pesquisa é 0 método hipotético- dedutivo, que pode ser descrito como o método da tentativa e erro; porque diante do problema e da conjectura, testa-se a hipótese, por meio da experimentação e/ou observação, a fim de rejeitar ou confirmar tal hipótese. (ARAGÃO e NETA, 2017).

\subsection{PROCEDIMENTOS METODOLÓGICOS}

Quanto aos procedimentos, entende-se como o processo necessário à realização de uma pesquisa. Portanto, o pesquisador precisa previamente estabelecer como, quando e onde coletar os dados. É um processo de tomada de decisão que busca alcançar um objetivo: encontrar respostas para suas perguntas.

RC: 84503

Disponível em: https://www.nucleodoconhecimento.com.br/administracao/forma-de-contribuir 
Esta pesquisa utiliza uma abordagem qualitativa. A pesquisa qualitativa apresenta um caráter mais subjetivo e seus procedimentos de coleta de dados têm como principal instrumento o pesquisador que - por meio de entrevistas, observação, questionários e bibliografias- faz a coleta dos dados, interpreta-os, confrontas as ideias e, assim, faz uma análise valorativa dos resultados obtidos.

\subsubsection{QUANTO À NATUREZA}

Dependendo da sua finalidade, a pesquisa pode ser classificada como pura/básica ou aplicada. Portanto, Gil (2017) declara que a pesquisa básica se destina a preencher o espaço existente no conhecimento, por sua vez, a pesquisa aplicada decorre de estudos que buscam solucionar problemas presentes nas sociedades.

Diante disso, este trabalho faz uso da pesquisa aplicada, na qual se propõe uma alternativa com possibilidade a solucionar o problema apresentado e assim colocar em prática o objetivo que se pretende com este estudo caso, de modo a alcançar um resultado positivo e que atenda às necessidades da instituição de ensino.

\subsubsection{QUANTO AOS FINS}

Esta pesquisa concentra-se em uma finalidade descritiva sobre $o$ assunto abordado, correlacionando suas características com a problemática em questão, a fim de que seja possível encontrar alternativas que visam atender o objetivo proposto. Conforme Gil (2017, p. 33) "As pesquisas descritivas têm como objetivo a descrição das características de determinada população ou fenômeno. Podem ser elaboradas também com a finalidade de identificar possíveis relações entre variáveis".

\subsubsection{QUANTO AOS MEIOS}

Refere-se à forma de como o pesquisador irá coletar os dados de que precisa. Todo profissional necessita de ferramentas para a realização de seu trabalho, instrumentos

RC: 84503

Disponível em: https://www.nucleodoconhecimento.com.br/administracao/forma-de-contribuir 
que viabilizem a realização de suas etapas, o meio pelo qual será possível alcançar seus objetivos.

Portanto, para o desenvolvimento desta pesquisa, utilizaram-se bibliografias, questionários, entrevistas com os gestores da escola, pesquisa de campo; bem como publicações, artigos e sites especializados na matéria.

\subsection{CARACTERIZAÇÃO DA EMPRESA}

A Escola Municipal Governador Eduardo Ribeiro, encontra-se localizado na Rua Santo Expedido, $\mathrm{n}^{\circ} 71$, bairro Cidade de Deus (antiga Fluminense) na área comercial do bairro, na Zona Norte de Manaus, CEP 69099-314, Manaus-AM.

A Escola Governador Eduardo Ribeiro atende alunos na faixa etária de 5 a 11 anos aproximadamente, residentes na sua maioria nas proximidades da escola. A maioria dos alunos são de classe baixa e média. Pais ou responsáveis exercem funções como pequenos comerciantes, autônomos, operários, diaristas, industriários.

A Escola oferece aos alunos a modalidade de Ensino Educação Infantil do $1^{\circ}$ ao $5^{\circ}$ ano do Ensino Fundamental, alimentação escolar, água filtrada e atividades pedagógicas para uma melhor aprendizagem dos alunos. Buscando garantir um constante aprendizado e o ensino de qualidade, a fim de que seus alunos possam receber efetivamente todo o cuidado e apoio de que precisam para a sua educação.

Seu objetivo é desenvolver atividades Sócio Político Pedagógicas favoráveis à efetivação da aprendizagem, à integração escola e comunidade e à Gestão participativa; visando à implementação de uma escola cidadã capaz de produzir e compartilhar conhecimentos e educar com responsabilidade e comprometimento, proporcionando meios para o pleno desenvolvimento do discente.

RC: 84503

Disponível em: https://www.nucleodoconhecimento.com.br/administracao/forma-de-contribuir 


\section{RESULTADOS E DISCUSSÕES}

Há muitos fatores que estão ligados direta ou indiretamente ao desempenho de uma organização, por exemplo, a falta de mão de obra em uma determinada instituição pode comprometer $\mathrm{o}$ andamento das atividades de um setor; bem como comprometer a qualidade dos serviços ou produtos oferecidos, o que influencia diretamente nas metas e objetivos que tal instituição pretende alcançar e, desse modo, apresentar um resultado abaixo do esperado.

Com base no diagnóstico organizacional realizado na Escola Municipal Governador Eduardo Ribeiro; identificou-se a média de desempenho por área funcional de cada um de seus departamentos, conforme o gráfico 1 a seguir.

Gráfico 1- Desempenho Por Área Funcional

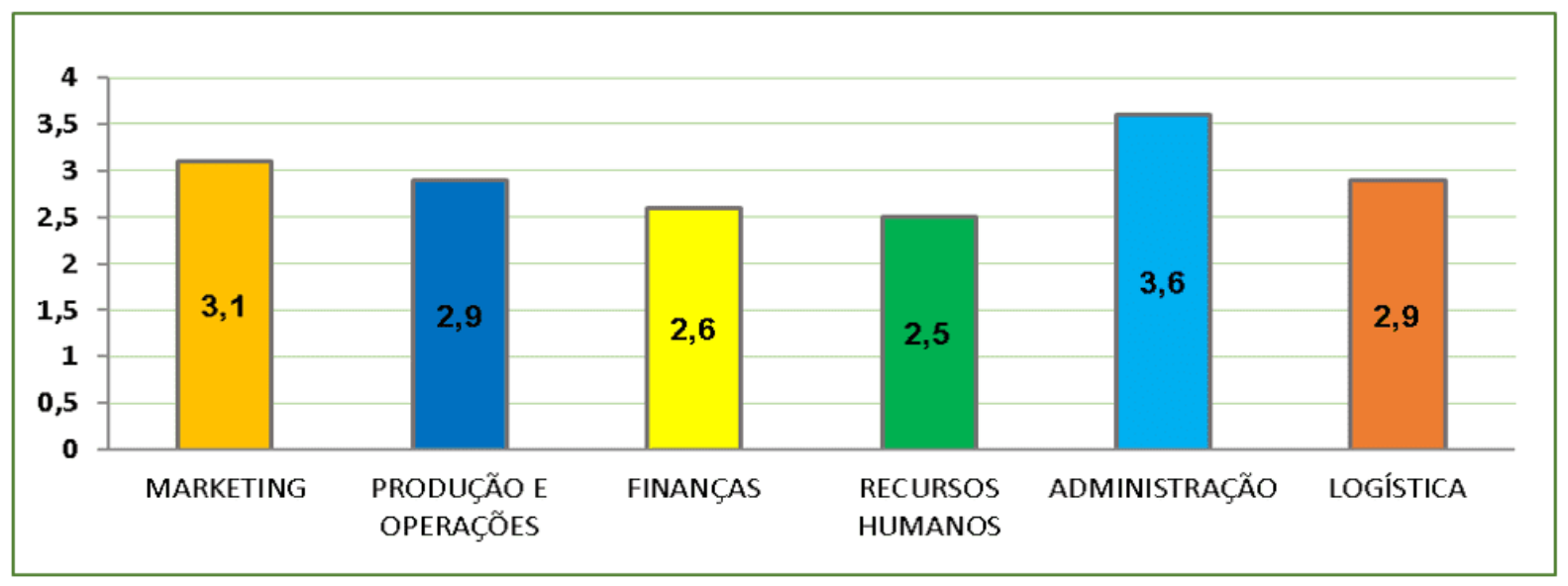

FONTE: Elaborado pelos autores da pesquisa, 2021.

Conforme exposto pelo gráfico, os departamentos de administração e marketing apresentam a melhor média de desempenho nas suas atividades, em seguida as áreas de operações, logística e finanças apresentam um bom desempenho; por sua vez, o departamento de recursos humanos mostra-se com o desempenho mais baixo em comparação com os outros departamentos.

RC: 84503

Disponível em: https://www.nucleodoconhecimento.com.br/administracao/forma-de-contribuir 
Nesse contexto, por meio deste diagnóstico, busca-se apresentar uma proposta de solução em que seja possível envolver as famílias no contexto escolar das crianças, como forma de contribuir para educação dos filhos, ou seja, participando da gestão escolar e preenchendo algumas necessidades da escola sempre que possível.

Diante disso, o departamento de recursos humanos da Escola Municipal Governador Eduardo Ribeiro apresenta alguns pontos críticos que influenciam na qualidade do ensino oferecido aos alunos, assim como nas outras atividades que demandam um apoio maior de pessoal para uma melhor aprendizagem por parte das crianças. $\mathrm{O}$ quadro a seguir revela alguns desses fatores críticos na escola.

Quadro 1- Área Funcional.

\begin{tabular}{|c|c|c|c|c|c|}
\hline AREAFUNCIONAL & \multicolumn{5}{|c|}{ NIVEL OU GRAU DE AVALIAÇÃO } \\
\hline RECURSOS HUMANOS & $\begin{array}{c}\text { Ponto } \\
\text { muito } \\
\text { forte } \\
5\end{array}$ & $\begin{array}{c}\text { Ponto } \\
\text { forte } \\
4\end{array}$ & $\begin{array}{c}\text { Ponto } \\
\text { médio } \\
3\end{array}$ & $\begin{array}{c}\text { Ponto } \\
\text { fraco } \\
2\end{array}$ & \begin{tabular}{|c} 
Ponto \\
muito \\
fraco \\
1
\end{tabular} \\
\hline \begin{tabular}{l|l} 
& A mão de obra disponivel na escola \\
\end{tabular} & & $x$ & & & \\
\hline 2 Aescola preza pela "Formalização das relaçoes trabalhistas vigente" & & & $\mathrm{x}$ & & \\
\hline 3 A rotatividade de pessoal está aceitavel ( Turnover) & & $x$ & & & \\
\hline 4 Aescola investe em programas de "Motivação dos trabalhadores" & & & & $x$ & \\
\hline 5 Aescola investe "Desenvolvimento técnico profissional" & & & & $x$ & \\
\hline 6 A escola estipula "Média de horas de formação por trabalhador" & & & & & $\mathrm{x}$ \\
\hline 7 Aescola possui progama de prevenção "Acidentes no local de trabalho" & & & & & $\mathrm{x}$ \\
\hline 8 Aescola possui programa de recrutamento e selecão estruturado & & $x$ & & & \\
\hline 9 As taxas de Absenteismo são aceitaveis & & & $\mathrm{x}$ & & \\
\hline 10 Aescola determina metas individuais de desempenho para cada colaborador & & & & & $x$ \\
\hline TOTAL ( $(\Sigma)$ & 0 & 12 & 6 & 4 & 3 \\
\hline MÉDIA POR GRAU (POR COLUNA) & 0 & 1,2 & 0,6 & 0,4 & 0,3 \\
\hline DESEMPENHO DA ÁREA & & & 2,5 & & \\
\hline
\end{tabular}

FONTE: Elaborados pelos autores da pesquisa, 2021.

O nível ou grau de avaliação demonstrado no quadro 1 acima, revela os pontos fortes e fracos apresentados pelo recursos humanos da escola, onde é possível identificar que o ponto forte 4 mostra que a rotatividade de pessoal está aceitável. Entretanto;

RC: 84503

Disponível em: https://www.nucleodoconhecimento.com.br/administracao/forma-de-contribuir 
considera-se um dos pontos muito fraco 1, a escola não determinar metas individuais de desempenho para cada colaborador ou equipe do departamento.

Diante disso, tal estudo visa apresentar possíveis soluções para os problemas encontrados; no sentido de também incluir as famílias dos alunos na gestão escolar participativa, para que assim elas possam contribuir com a manutenção das dependências da escola e de outras necessidades que ela apresenta, buscando sempre oferecer uma educação de qualidade para os alunos, bem como para as famílias e comunidade que dependem dessa escola.

\subsection{DESCRIÇÃO DAS AÇÕES INTERVENTIVAS}

As ações interventivas proposta pela pesquisa apresentam-se como possíveis soluções para solucionar alguns dos problemas apresentados pela instituição de ensino. Pois, através dessas ações, cria-se a oportunidade das famílias estarem presentes e ativas no contexto escolar, participando, aprendendo, compartilhando e contribuindo de forma prática com a educação das crianças da escola. Tais ações estão descritas no quadro 2 a seguir:

Quadro 2 - Ações Interventivas.

\begin{tabular}{|c|c|c|c|c|}
\hline & Ações Interventivas & Cronologia & Duração & Custo \\
\hline 1 & $\begin{array}{l}\text { Palestras educativas sobre prevenção de } \\
\text { acidentes. }\end{array}$ & Maio de 2021 & $\begin{array}{c}\text { Uma vez por } \\
\text { semana }\end{array}$ & 500,00 \\
\hline 2 & $\begin{array}{l}\text { Palestras motivacionais sobre desempenho } \\
\text { e clima organizacional. }\end{array}$ & Junho de 2021 & $\begin{array}{l}\text { Duas vezes } \\
\text { por semana }\end{array}$ & $\mathrm{R} \$ \quad 500,00$ \\
\hline 3 & $\begin{array}{l}\text { conciliar as habilidades profissionais dos } \\
\text { pais com as necessidades da escola. }\end{array}$ & $\begin{array}{l}\text { Maio a Outubro } \\
\text { de } 2021\end{array}$ & $\begin{array}{c}\text { Uma vez por } \\
\text { semana }\end{array}$ & 600,00 \\
\hline 4 & $\begin{array}{l}\text { Fazer a manutênção periódica das } \\
\text { dependências e instalações da escola }\end{array}$ & $\begin{array}{l}\text { Maio a Outubro } \\
\text { de } 2021\end{array}$ & $\begin{array}{l}\text { A cada } 15 \\
\text { dias }\end{array}$ & $\mathrm{R} \$ 1.200,00$ \\
\hline 5 & $\begin{array}{l}\text { Desenvolver a técnica de Brainstorming na } \\
\text { escola }\end{array}$ & $\begin{array}{l}\text { Maio a Outubro } \\
\text { de } 2021\end{array}$ & $\begin{array}{l}\text { A cada } 15 \\
\text { dias }\end{array}$ & 600,00 \\
\hline 6 & $\begin{array}{l}\text { Instalar um kit de câmeras de vigilância } \\
\text { eletrônica }\end{array}$ & Maio de 2021 & 24 horas & $\mathrm{R} \$ 1.300,00$ \\
\hline
\end{tabular}

FONTE: Elaborado pelos autores da pesquisa, 2021.

RC: 84503

Disponível em: https://www.nucleodoconhecimento.com.br/administracao/forma-de-contribuir 


\subsection{MÉTODO DE EXECUÇÃO DAS AÇÕES INTERVENTIVAS}

Para qualquer objetivo que se pretenda alcançar, é preciso ter de antemão um método que possa estabelecer, demonstrar, descrever o passo a passo das etapas que serão necessárias para alcançar o fim que se deseja. Um mapa, com uma visão clara do caminho a ser percorrido na realização das tarefas, dos processos, das atividades a serem desenvolvidas. Pois quando se tem uma visão clara de onde ser quer chegar, fica mais fácil atingir o objetivo.

De tal modo, as ações interventivas aqui proposta serão implementadas por meio da ferramenta $5 \mathrm{~W} 2 \mathrm{H}$. Tal método tem por objetivo facilitar a execução de um plano de ação, pois é uma ferramenta que descreve os dados essenciais para que uma determinada tarefa possa ser realizada, demonstra praticidade e é de fácil compreensão.

Segundo Bassan (2018), por meio dessa ferramenta, definem-se as questões fundamentais que estão envolvidas no processo de desenvolvimento dos planos de ações e a descrição das responsabilidades quanto à realização das tarefas, criando uma visão estruturada das atividades de modo a permitir o seu acompanhamento.

\subsection{PALESTRAS EDUCATIVAS SOBRE PREVENÇÃO DE ACIDENTES}

A ação interventiva 1, descrita no quadro 3 a seguir, busca, prioritariamente, resguardar a integridade física e a vida de todos que circulam nas dependências da escola, colaborando para que haja uma atenção sobre os possíveis perigos que podem acarretar em acidentes. Uma medida que trabalha com o foco na prevenção de acidentes e preza pela qualidade de vidas de todos que transitam na escola.

RC: 84503

Disponível em: https://www.nucleodoconhecimento.com.br/administracao/forma-de-contribuir 
Quadro 3 - 5w2h - Ação Interventiva 1

\begin{tabular}{|c|c|l|}
\hline \multicolumn{3}{|c|}{ PALESTRAS EDUCATIVAS SOBRE PREVENÇÃO DE ACIDENTES } \\
\hline WHAT & O QUE? & Conscientizar, alunos, professores, familias, colaboradores \\
\hline WHO & QUEM? & Palestrante convidado \\
\hline WHY & POR QUE? & Para previnir a ocorrência de acidentes na escola \\
\hline WHERE & ONDE? & Na escola \\
\hline WHEN & QUANDO & Maio de 2021 \\
\hline HOW & COMO? & Apresentações, Mídia Socias da escola, Mural da escola \\
\hline HOW MUCH & QUANTO? & R\$ 500.00 \\
\hline
\end{tabular}

FONTE: Elaborado pelos autores da pesquisa, 2021.

Assim, a ação interventiva 1 pretende conscientizar todos os participantes da escola sobre as causas de acidentes mais comuns, decorrentes da falta de atenção, negligência, imperícia e outros fatores que colocam ou podem colocar em risco a integridade física e a vida dos alunos, professores, colaboradores, país e gestores da escola; uma vez que, conhecendo tais causas, fica mais fácil providenciar a sinalização, alertar sobres os perigos do local e dessa forma evitar acidentes.

\subsection{PALESTRAS MOTIVACIONAIS SOBRE DESEMPENHO ORGANIZACIONAL}

Oferecer uma educação de qualidade é um grande desafio para muitas escolas públicas e privadas, pois muitos fatores influenciam positiva ou negativamente na qualidade do ensino que é transmitida aos alunos.

Criar e manter a motivação e o bom desempenho dos colaboradores, em um ambiente de trabalho saudável, que os motiva a continuar empenhados nas tarefas e no atingimento das metas e objetivos passam a ser um desafio diário para as organizações, porque isso também pode contribuir ou comprometer seus resultados.

RC: 84503

Disponível em: https://www.nucleodoconhecimento.com.br/administracao/forma-de-contribuir 
Para Merluzzi (2020) a motivação é aquela que incentiva as pessoas a fazerem aquilo que precisa ser feito e, afim de se manter sustentável, precisa estar pautada na realização e desenvolvimento pessoal, satisfação e reconhecimento profissional, onde o ambiente de trabalho tenha um clima de respeito, transparência e confiança.

Pois, um bom clima organizacional e colaboradores motivados têm grande relevância no desempenho da instituição, o que pode ser percebido na qualidade dos serviços ou produtos que são oferecidos aos clientes; tornando-se um divisor de águas que pode manter sua competitividade por muito mais tempo no mercado.

Quadro 4 - 5w2h - Ação Interventiva 2

\begin{tabular}{|c|c|l|}
\hline \multicolumn{3}{|c|}{ PALETRAS MOTIVACIONAIS DE DESEMPENHO E CLIMA ORGANIZACIONAL } \\
\hline WHAT & O QUE? & Conscientizar os colaboradores da escola e motivá-los \\
\hline WHO & QUEM? & Palestrante convidado \\
\hline WHY & POR QUE? & Para um melhor desempenho dos colaboradores \\
\hline WHERE & ONDE? & Na escola \\
\hline WHEN & QUANDO & Junho de 2021 \\
\hline HOW & COMO? & Apresentações e Dinâmica com os colaboradores \\
\hline HOW MUCH & QUANTO? & R\$ 700.00 \\
\hline
\end{tabular}

FONTE: Elaborado pelos autores da pesquisa, 2021.

Assim, a ação interventiva 2 procura salientar sobre a importância de se manter um bom clima organizacional na escola e de como isso pode contribuir para um melhor desempenho das atividades que cada colaborador procura desenvolver e também motivá-los, mostrando-lhes a sua importância para escola, seu papel e sua contribuição com os serviços que são prestados aos alunos e, assim, promover uma melhor aprendizagem por parte das crianças e uma educação de qualidade. 


\subsection{PROFISSÕES DOS PAIS E NECESSIDADES DA ESCOLA}

É evidente que a educação e o conhecimento repassados em sala de aula não estão apenas a cargo do professor; pois, junto com ele, há também gestores e outros profissionais que são necessários e dão suporte para que os alunos recebam de fato um ensino de qualidade. No entanto, nem sempre as escolas da rede pública dispõem de recursos humanos suficientes para atender às suas demandas, e a falta desse recurso pode comprometer $\mathrm{o}$ andamento das suas atividades.

Nesse sentido, a ação interventiva 3 visa possibilitar a participação da família na gestão escolar participativa por meio de alguma necessidade da escola. Pois procurase, dessa forma, estabelecer uma equiparação entre as habilidades profissionais que os pais dos alunos podem oferecer com uma demanda que a escola apresenta, ou seja, dando-lhes a chance de conhecer e contribuir com tudo que diz respeito à educação de seus filhos; entendo que a educação não depende apenas do professor em sala de aula, mas também envolve outros fatores para que as crianças recebam efetivamente um ensino de qualidade na sala de aula.

Quadro

5

$5 w 2 h$

Ação

Interventiva

3

CONCILIAR AS PROFISSÕES DOS PAIS COM AS NECESSIDADE ESCOLARES

\begin{tabular}{|c|c|l|}
\hline WHAT & O QUE? & Possibilitar a gestão participativa \\
\hline WHO & QUEM? & Pais e gestores da escola \\
\hline WHY & POR QUE? & Promover a inclusão da família na escola \\
\hline WHERE & ONDE? & Na escola \\
\hline WHEN & QUANDO & Maio a Outubro de 2021 \\
\hline HOW & COMO? & Sumprindo uma necesidade da escola \\
\hline HOWMUCH & QUANTO? & R\$ 600.00 \\
\hline
\end{tabular}

FONTE: Elaborado pelos autores da pesquisa, 2021.

RC: 84503

Disponível em: https://www.nucleodoconhecimento.com.br/administracao/forma-de-contribuir 
Dessa forma, permite-se incluir a família na gestão escolar e possibilita uma participação mais efetiva no que diz respeito aos pais se envolverem com o ambiente escolar dos filhos. Portanto, conhecer os aspectos, as necessidades e as demandas que permeiam a educação das crianças abre a oportunidade de os pais preencherem esses espaços e assim demonstrar um apoio maior na aprendizagem dos alunos.

\subsection{MANUTENÇÃO PERIÓDICA DAS DEPENDÊNCIAS DA ESCOLA}

$\mathrm{Na}$ tarefa de educar, o espaço escolar, isto é, suas dependências e infraestrutura também faz uma grande diferença quando se trata de oferecer um ensino de qualidade aos alunos; uma vez que dispor de uma escola bem-organizada, que tenha um ambiente seguro, acolhedor e bem conservado, transmite a toda comunidade escolar o quanto a educação é importante naquela instituição.

Desse modo, o espaço escolar é o lugar onde muitas crianças e jovens passam uma boa parte de seu tempo. É nesse local que é possível ensinar e aprender, não apenas na sala de aula; mas em todos os seus ambientes. Pois sua infraestrutura, bem como sua manutenção também demonstram a importância e o respeito como a vida dos alunos e com sua educação. (CEDAC, 2013).

Logo, e nesse espaço que crianças, jovens, adultos e colaboradores desenvolvem uma relação social, compartilham suas experiências de vida transmitem e recebem conhecimento durante todo o período escolar; por isso é importante que ela seja bemorganizada e preparada para recepcionar bem a todos, revelando o respeito, a qualidade, a transparência e a atenção que é dedicada a toda comunidade escolar.

RC: 84503

Disponível em: https://www.nucleodoconhecimento.com.br/administracao/forma-de-contribuir 
Quadro 6 - 5w2h - Ação Interventiva 4.

\begin{tabular}{|c|c|l|}
\hline \multicolumn{3}{|c|}{ MANUTENÇÃO REGULAR DAS DEPENDÊNCIAS E INSTALAÇÕES DA ESCOLA } \\
\hline WHAT & O QUE? & Manter a infaestrutura da escola \\
\hline WHO & QUEM? & Familias, alunos, comunidade, colaboradores, gestores \\
\hline WHY & POR QUE? & Para preservar o patrimônio escolar das crianças \\
\hline WHERE & ONDE? & Na escola \\
\hline WHEN & QUANDO & Maio a Outubro de 2021 \\
\hline HOW & COMO? & Formar equipes para, zelar, organizar e preservar \\
\hline HOW MUCH & QUANTO? & R\$ 1.200,00 \\
\hline
\end{tabular}

FONTE: Elaborado pelos autores da pesquisa, 2021.

Desse modo, a ação interventiva 4 promove a participação das famílias, alunos, professores, gestores, colaboradores e comunidade na manutenção regular das dependências da escola, com o intuito de cuidar de sua infraestrutura, zelar, preservar e proteger o patrimônio escolar das crianças.

Assim, tem-se a oportunidade também de oferecer um ensino de qualidade, por meio de uma escola organizada e em perfeito estado; contribuindo para o bem-estar de todos os envolvidos e assim se beneficiar de um ambiente escolar seguro, agradável e em ótimas condições.

\subsection{DESENVOLVER A TÉCNICA DE BRAINSTORMING NA ESCOLA}

A ação interventiva 5 tem por objetivo aplicar a técnica de brainstorming na escola, que é uma técnica que busca estimular a criatividade de seus participantes, por meio de uma tempestade de ideias, em que todos são motivados a contribuir com qualquer ideia que lhes vem à mente, sem a preocupação de estarem certos ou errados; pois

RC: 84503

Disponível em: https://www.nucleodoconhecimento.com.br/administracao/forma-de-contribuir 
assim será possível manter um repertório de ideias que poderão ser analisadas, desenvolvidas, descartadas, bem como permitir a solução para problemas.

Bassan (2018) descreve que por meio dessa técnica são desenvolvidas atividades de criação de um leque de sugestões e ideias, com a finalidade de encontrar melhorias para uma determinada situação ou que seja possível resolver problemas; dentro de uma dinâmica de grupo, como o ponto de partida, na qual possa existir liberdade para propor ideias e encontrar soluções.

Quadro 7 - 5w2h - Ação Interventiva 5

\begin{tabular}{|c|c|l|}
\hline \multicolumn{3}{|c|}{ DESENVOLVER A TÉCNICA DE BRAINS TORMING NA ESCOLA } \\
\hline WHAT & O QUE? & Promover debates e discursão de ideias \\
\hline WHO & QUEM? & Gestores, colaboradores, alunos, familias e comunidade \\
\hline WHY & POR QUE? & Para discutir ideias e solução de problemas da escola \\
\hline WHERE & ONDE? & Na escola \\
\hline WHEN & QUANDO & Maio a Outubro de 2021 \\
\hline HOW & COMO? & Por meio de reuniões, apresentações e dinâmicas \\
\hline HOW MUCH & QUANTO? & R\$ 600,00 \\
\hline
\end{tabular}

FONTE: Elaborado pelos autores da pesquisa, 2021.

Portanto, ao promover a técnicas de brainstorming na escola, colaboradores, alunos, país, professores e comunidade terão a chance de contribuir com ideias para a criação de projetos escolares, assim como encontrar soluções para resolver os problemas que a escola apresenta. Pois, assim, tem-se a chance de todos os envolvidos contribuir, elaborar, desenvolver, permitir e participar de uma escola que apresenta um arsenal de ideias e soluções que colabora para um ensino de qualidade.

RC: 84503

Disponível em: https://www.nucleodoconhecimento.com.br/administracao/forma-de-contribuir 


\subsection{CAMERAS DE VIGILÂNCIA ELETRÔNICA}

Muitas escolas da rede pública de ensino têm sofrido diversos assaltos dentro ou nos arredores das escolas; principalmente nos finais de semana. Nesse período não há expediente e é quando as escolas ficam mais vulneráveis à ação de bandidos.

Como consequência, o resultado dessa violência reflete diretamente na educação dos alunos. Computadores, televisores, aparelhos e outros materiais que são necessários ao andamento das aulas e das outras atividades são furtados, muitos documentos são perdidos e as dependências da escola são destruídas, advindo prejuízos que dificultam e atrasam o progresso dos alunos na sala de aula.

Diante disso, a ação interventiva 6 apresenta-se como uma medida de segurança que visa proteger o patrimônio escolar dos alunos e garantir o mínimo de segurança às crianças, professores, gestores, país e colaboradores; bem como manter o controle de acesso às dependências da escola por pessoas estranhas, visto que a escola não dispõe de um porteiro ou vigilante, buscando, assim, limitar a ação de assaltantes contra a escola.

RC: 84503 
Quadro 8 - 5w2h - Ação Interventiva 6.

\begin{tabular}{|c|c|l|}
\hline \multicolumn{3}{|c|}{ INSTALAÇÃO DE CAMERAS DE VIGILÂNCIA ELETRÔNICA } \\
\hline WHAT & O QUE? & Vigilância Eletrônica \\
\hline WHO & QUEM? & Técnico de CFTV \\
\hline WHY & POR QUE? & Para garantir segurança, proteção e controle de acesso \\
\hline WHERE & ONDE? & Na escola \\
\hline WHEN & QUANDO & Maio de 2021 \\
\hline HOW & COMO? & Por meio das cameras de vigilância \\
\hline HOW MUCH & QUANTO? & R\$ 1.300,00 \\
\hline
\end{tabular}

FONTE: Elaborado pelos autores da pesquisa, 2021.

Em relação à segurança patrimonial, câmeras de vigilância eletrônica tornam-se necessárias, com isso procura-se oferecer segurança para todos que estão na escola, proteger o patrimônio escolar, impedir o acesso de pessoas estranhas que podem representar uma ameaça às crianças e também permitir a identificação dessas pessoas não autorizadas a estarem nas dependências da escola.

\section{CONSIDERAÇÕES FINAIS}

A educação infantil no brasil ainda passa por muitos obstáculos no que se refere a oferecer uma educação de qualidade às crianças. Esses obstáculos precisam ser superados diariamente por toda a comunidade escolar para que os alunos recebam um ensino com qualidade e assimilem verdadeiramente o conhecimento transmitido na sala de aula.

Nesse sentido, a escola tem um papel essencial na formação dos alunos e deve sempre está atenta às suas necessidades; bem como permitir, promover e criar condições que deem a eles a oportunidade de fazerem parte de uma escola que

RC: 84503

Disponível em: https://www.nucleodoconhecimento.com.br/administracao/forma-de-contribuir 
transmiti o saber com eficiência, preza pela qualidade do ensino e oferece condições seguras e adequadas a todos da comunidade escolar, dentro de um ambiente escolar que está alicerçado em oferecer uma educação de excelência.

Por sua vez, as famílias também têm sua importância e representam um papel fundamental na vida dos alunos e na sua eterna missão de educar. Sabendo que sua contribuição tem grande relevância, é imprescindível sua participação ativa e permanente em tudo que envolve a educação de seus filhos, cumprindo seu papel afetivo e social de educar para a vida e prepará-los para o mundo que os cerca.

Nesse contexto, o estudo de caso realizado na Escola Municipal Governador Eduardo Ribeiro encontrou algumas deficiências que a escola apresenta. Diante disso, esta pesquisa procurou entender o contexto da escola, suas limitações e muitos outros problemas que têm dificultado a sua árdua tarefa de oferecer aos alunos uma educação de excelência.

Por meio das ações interventivas aqui apresentadas, as famílias podem também se envolverem ativamente no contexto da escola, contribuindo de forma prática com a educação de seus filhos e assim fazendo parte desse processo educacional constantemente e não apenas de forma esporádica

Ademais, tal estudo procura propor algumas ações para que a escola e as famílias apresentem um melhor desempenho no quesito educação e contribuam para o desenvolvimento educacional das crianças dessa escola. Sem, entretanto, definir regras ou obrigações; mas simplesmente ajudá-las a encontrar um caminho que as direcionem sempre no objetivo de prestar aos seus alunos a melhor educação, com eficiência e qualidade que eles merecem.

Dessa forma, procura-se ajudar as famílias a estarem inseridas no contexto escolar da Escola Municipal Governador Eduardo Ribeiro de forma prática, como forma de contribuir com a educação das crianças dessa escola; por meio da preservação do

RC: 84503

Disponível em: https://www.nucleodoconhecimento.com.br/administracao/forma-de-contribuir 
patrimônio escolar dos seus filhos, do cuidado, do zelo com a infraestrutura da escola e também suprindo alguma necessidade que ela apresenta.

Por outro lado, há também a oportunidade de os país fazerem parte da gestão da escola no que se refere à tomada de decisão, ou seja, sobre o melhor caminho que a escola pode seguir; assim como desempenhar papéis ativos na construção do projeto político-pedagógico, dentro de uma gestão democrática e participativa.

Portanto, todo trabalho desenvolvido neste estudo de caso procura demonstrar a importância que a família tem no ambiente escolar e como a sua participação pode contribuir para o progresso da educação em todos os seus aspectos; bem como ressaltar a importância da escola. Uma instituição que é essencial na vida dos estudantes e que desempenha uma função socioeducacional de grande valor à sociedade e à educação, por isso precisa ser respeitada, valorizada e preservada por todos da comunidade escolar.

\section{REFERÊNCIAS}

ARAGÃO, José Wellington Marinho de; NETA, Maria Adelina Hayne Mendes. Metodologia Científica. Recurso eletrônico. Salvador: UFBA, Faculdade de Educação, Superintendência de Educação a Distância, 2017, p. 28 a 37.

BASSAN, Edilberto José. Gestão da Qualidade: Ferramentas, Técnicas, Métodos. 1. ed. Curitiba - PR: Edilberto Bassan, 2018, p. 8 a 113. Disponível em: https://www.amazon.com.br/GEST\%C3\%830-QUALIDADE-FerramentasT\%C3\%A9cnicas-M\%C3\%A9todos-ebook/dp/B07H7NPJDY. Acesso em 17/03/2021

CEDAC, Comunidade Educativa. Diálogo escola-família: Parceria para a aprendizagem e o desenvolvimento integral de crianças, adolescentes e jovens / organização Tereza Perez. São Paulo: Moderna, 2019, p. 5 a 207. Disponível em: https://comunidadeeducativa.org.br/wpcontent/uploads/2019/06/Dia\%CC\%81logo_site.pdf. Acesso em: 27/03/2021.

RC: 84503

Disponível em: https://www.nucleodoconhecimento.com.br/administracao/forma-de-contribuir 
CEDAC, Comunidade Educativa. 0 que revela o espaço escolar? Um livro para diretores de escola.1. ed. São Paulo: Moderna, 2013, p. 9 a 176. Disponível em: https://www.moderna.com.br/lumis/portal/file/fileDownload.jsp?fileld=8A8A8A833E8B A005013E9E000E650B9C. Acesso em: 27/03/2021.

CHEMIN, Beatris Francisca. Manual da Univates para trabalhos acadêmicos. 2. ed. Lajeado: Ed. da Univates, 2012, p. 39 a 79. Disponível em: https://www.univates.br/editora-univates/media/publicacoes/19/pdf_19.pdf. Acesso em: 28/03/2021.

FERREIRA, Carla Hariele. Discutindo a relação família-escola na educação infantil: Reflexões a partir da perspectiva de mães. Trabalho de Conclusão de Curso (Graduação em Psicologia) - Universidade Federal de Uberlândia, 2018, p. 1 a 31. Disponível em: https://repositorio.ufu.br/handle/123456789/26124. Acesso em: 27/03/2021.

GIL, Antonio Carlos, 1946. Como elaborar projetos de pesquisa. 6. ed. São Paulo: Atlas, 2017, p. 32 a 53.

LAKATOS, Eva Maria; MARCONI, Marina de Andrade. Fundamentos de metodologia científica. 8. ed. São Paulo: Atlas, 2017, p. 59 a 80.

LUCK, Heloísa. Gestão educacional: Uma questão paradigmática. ed. digital. Petrópolis - RJ: vozes, 2017, p. 619 a 938, v. I. Série Cadernos de Gestão. Disponível em: $\quad$ https://www.amazon.com.br/Gest\%C3\%A3o-educacional-quest\%C3\%A3oparadigm\%C3\%A1tica-Cadernosebook/dp/B074JDQ8Y4/ref=tmm_kin_swatch_0?_encoding=UTF8\&qid=\&sr= sítio. Acesso em: 13/03/2021.

MACHADO, Igor José de Renó; AMORIN, Henrique; BARROS, Celso Rocha de. Da escola para o mundo: Projetos integradores: Ciências humanas e sociais aplicada.

RC: 84503

Disponível em: https://www.nucleodoconhecimento.com.br/administracao/forma-de-contribuir 
V. único. 1. ed. São Paulo: Ática, 2020, p. 211 a 220. Disponível em: https://edocente.educar.tech. Acesso em 28/03/2021.

MERLUZZI, Orlando. Potência corporativa: Transformando o clima organizacional e a adrenalina em resultados para a organização. 2. ed. Atualizada e ampliada. São Paulo -SP: Pensamento Corporativo,2020, p. 10 a 89. Disponível em: https://www.amazon.com.br/Pot\%C3\%AAncia-Corporativa-Transformandoorganizacional-organiza\%C3\%A7\%C3\%A3oebook/dp/B08SKRF2QL/ref=sr_1_1?_mk_pt_BR=\%C3\%85M\%C3\%85\%C5\%BD\% $\mathrm{C} 3 \% 95 \% \mathrm{C} 3 \% 91$ \&dchild=1\&keywords=Pot\%C3\%AAncia+corporativa\%3A+transform ando+o+clima+organizacional+e+a+adrenalina+em+resultados+para+a+organiza\%C 3\%A7\%C3\%A3o.\&qid=1616792833\&s=digital-text\&sr=1-1. Aceso em: 18/03/2021.

SANTANA, Katiane Cardoso. A influência da família e da escola na formação integral da criança. Anais III CONEDU. Campina Grande: Realize Editora,2016, p. 1 a em: https://www.editorarealize.com.br/index.php/artigo/visualizar/19929>. Acesso em: 27/03/2021.

SILVA, Luciana Duarte. Impactos da educação: Relação família e escola. Revista do IGES - Ano 1 n. 1, maio de 2017 - Artigo 8, p. 50 a 59. Disponível em: http://www.igesrs.com.br/publi/Ano1.pdf. Acesso em 27/03/2021.

Enviado: Março, 2021.

Aprovado: Maio, 2021.

RC: 84503

Disponível em: https://www.nucleodoconhecimento.com.br/administracao/forma-de-contribuir 